\title{
PRODUTIVIDADE DE GRÃOS DE TRIGO EM FUNÇÃO DA INOCULAÇÃO COM Azospirillum brasilense E ADUBAÇÃO NITROGENADA
}

\author{
Tiago Aranda Catuchi ${ }^{1,2}$, Lyon Monteiro ${ }^{1}$, Carlos Sérgio Tiritan ${ }^{1}$, Alexandrius de \\ Moraes Barbosa', Fernando Vieira Costa Guidorizzi ${ }^{1}$
}

${ }^{1}$ Universidade do Oeste Paulista - UNOESTE, Grupo de Pesquisa Agropecuária do Oeste Paulista - GPAGRO, Rodovia Raposo Tavares, Km 572, CEP: 19.067-175, Presidente Prudente(SP).ㄹmail: tiago@unoeste.br

RESUMO: O objetivo deste trabalho foi estudar a influência da inoculação de sementes de trigo com bactérias do gênero Azospirillun brasilense, em interação com a aplicação de nitrogênio, sobre a produtividade e qualidade do trigo. $\mathrm{O}$ experimento foi conduzido durante os meses de abril a setembro de 2010, no município de São João do Ivaí - PR. O delineamento experimental utilizado foi em blocos inteiramente casualizados, com quatro repetições, no esquema fatorial $2 x$ 4 , considerando tratamentos com e sem inoculação das sementes por bactérias fixadoras de nitrogênio, em interação à doses de nitrogênio aplicadas em cobertura $\left(0,65,100\right.$ e $145 \mathrm{~kg} \mathrm{ha}^{-1}$ de N). Avaliou-se a massa de 1000 grãos, o número de espiguetas, o peso hectolitro $(\mathrm{PH})$ e a produtividade dos grãos. $\mathrm{A}$ produtividade de grãos de trigo foi de 5,0 sacas ha- ${ }^{-1}$ a mais no tratamento em que se utilizou a inoculação com as bactérias. Além da produtividade o $\mathrm{PH}$ também foi influenciado pela inoculação, sendo que o PH foi maior quando se realizou a inoculação na dose 0 e de $125 \mathrm{~kg} \mathrm{ha}^{-1}$ de $\mathrm{N}$. Quanto à massa de 1000 grãos, observou-se também efeito positivo da inoculação, no tratamento inoculado a massa de 1000 grãos foi de $41,75 \mathrm{~g}$, no tratamento que não recebeu inoculação a massa foi de $37,92 \mathrm{~g}$.

Palavras-chave: Triticum aestivum, bactérias fixadoras de nitrogênio, doses de nitrogênio.

\section{PRODUCTIVITY OF WHEAT GRAINS FOR EACH INOCULATION WITH Azospirillum brasilense AND NITROGEN}

\begin{abstract}
The aim of this study was to investigate the influence of inoculation of wheat seeds with bacteria of the genus Azospirillun brasilense, interacting with nitrogen application on yield and quality of wheat. The experiment was conducted during the months of April to September 2010, in São João do Ivai - PR. The experiment was conducted in a randomized complete block design with four replications and $2 \times 4$ factorial considering treatments with and without seed inoculation by nitrogen-fixing bacteria in the interaction rates of nitrogen applied $(0$, 65,100 and $145 \mathrm{~kg} \mathrm{~N} \mathrm{ha}^{-1}$ ). We evaluated the mass of 1000 grains, number of spikelets, hectoliter weight (HW) and productivity of grains. Grain yield of wheat was 5.0 sacks over the ha- ${ }^{-}$treatment that was used to inoculation with bacteria. Besides the $\mathrm{pH}$ productivity was also influenced by the inoculation, and the $\mathrm{pH}$ was higher when inoculation was carried out at a dose of 0 to $125 \mathrm{~kg} \mathrm{ha}^{-1} \mathrm{~N}$. As to the mass of 1000 grains was also observed positive effect of inoculation, treatment inoculated mass of 1000 grains was $41.75 \mathrm{~g}$, the treatment did not receive the mass inoculation was $37.92 \mathrm{~g}$.
\end{abstract}

Key words: Triticum aestivum, nitrogen fixing bacteria, nitrogen levels. 


\section{INTRODUÇÄO}

O nitrogênio participa de papeis vitais na planta, principalmente na fotossintese e na respiração, além de constituir aminoácidos e proteínas. A participação do $\mathrm{N}$ na fotossíntese pode ser explicada pela atuação deste nutriente na sintese de clorofila e pelo seu papel na sintese da enzima Rubisco, que promove a fixação do $\mathrm{CO}_{2}$ atmosférico (TAIZ \& ZEIGER, 2009). Plantas bem nutridas com N possuem sistema radicular mais desenvolvido em razão da maior expansão da área foliar, sendo assim o $\mathrm{N}$ promove um aumento na taxa fotossintética, favorecendo o crescimento das raízes devido ao maior fluxo de carboidratos (PRADO, 2008). O N é o nutriente absorvido em maior quantidade pelas plantas, sendo o principal elemento limitador da produtividade da maioria das culturas (LOPES et al., 2004; PRADO, 2008). Em especial, na cultura do trigo, este nutriente determina o número de perfilhos, sendo mais essencial na fase de formação dos nós, no início do alongamento (DOBBELAERE et al., 2002).

A adubação nitrogenada na cultura do trigo é recomendada de acordo com a cultura antecedente (leguminosas ou gramíneas) que pode variar de 10 a $90 \mathrm{~kg}$ de $\mathrm{N} \mathrm{ha}^{-1}$ (EMBRAPA, 2009). As plantas conseguem utilizar apenas $50 \%$ do fertilizante nitrogenado aplicado como adubo, metade é perdida via lixiviação e desnitrificação (DOBBELAERE et al., 2002).

O adubo nitrogenado tem alto custo energético para sua obtenção, e são insumos de elevado custo para o produtor. Neste sentido práticas agrícolas, que aumentem a eficiência, ou minimizem a utilização de adubação nitrogenada, favorecem a obtenção de renda pelos produtores. Considerando que os vegetais são incapazes de utilizar nitrogênio atmosférico diretamente, mas podem obter nitrogênio através de fertilizantes nitrogenados ou fixado através de microrganismos que convertem o nitrogênio atmosférico em amônio (PEDROSA, 1987), as bactérias promotoras de crescimento de plantas (BPCP) podem auxiliar por diversos mecanismos na nutrição nitrogenada das culturas.

As BPCP são um grupo de microrganismos benéficos às plantas devido a capacidade de colonizar a superficie das raízes, rizosfera, filosfera e tecidos internos das plantas, podendo estimular o crescimento das plantas principalmente pela capacidade de fixação biológica de nitrogênio, além da atuação na produção de hormônios e solubilização de fosfato (HUNGRIA, 2011).

As BPCP mais estudadas são as bactérias pertencentes ao gênero Azospirillum, que possuem vida livre sendo encontrado em quase todos os lugares da terra (HUNGRIA, 2011; BASHAN \& DEBASHAN, 2005). Essas bactérias destacamse na produção de hormônios, que interferem no crescimento das plantas e podem alterar a morfologia das raizes, possibilitando a exploração de maior volume de solo (BASHAN \& HOGUIN, 1997; ZAIED et al., 2003), sendo que a principal função das mesmas é no aumento do processo da redução assimilatória de nitrato disponivel no solo (BODDEY et al., 1986) e a fixação biológica do $\mathrm{N}_{2}$ (INIGUEZ et al., 2004).

Em estudo bibliográfico realizado em todo mundo até 1994, Okon \& LabanderaGonzalez (1994) observaram respostas positivas em $70 \%$ dos trabalhos levantados, com aumento do rendimento de 5 a $30 \%$ em diversas culturas inoculadas com Azospirillum.

Campos et al. (1999) não encontraram nenhum efeito da inoculação das sementes com bactérias do gênero Azospirillum sobre o rendimento de grãos de trigo. Já Didonet et al. (2000) observaram que a inoculação das sementes de trigo com Azospirillum proporcionou melhor aproveitamento do $\mathrm{N}$ acumulado na biomassa da planta, translocando mais eficientemente o $\mathrm{N}$ para os grãos, produzindo grãos mais pesados. Mendes et al. (2011) também observaram respostas positivas com o uso das bactérias do gênero Azospirillum, sendo que esta inoculação aumentou o peso hectolitro e a produtividade dos grãos de trigo.

Estudos abordando a inoculação de 
Azospirillum com diferentes doses de adubação nitrogenada já vem sendo realizados, porém, diferentes classes de respostas vendo sendo observadas. Rodrigues et al. (2000) avaliando a resposta da cultura do trigo em função da inoculação com Azospirillum em interação com doses de $\mathrm{N}$, observaram maior teor de $\mathrm{N}$ no grão, porém não houve respostas significativas no rendimento de grãos. Sala et al. (2007) constataram que houve aumento na produtividade quando se fez a inoculação de Azospirillum, sendo que o maior incremento foi obtido quando não se utilizou nitrogênio adicional.

Sabe-se que o suprimento de $\mathrm{N}$ via fertilização mineral influencia o processo de FBN em leguminosas, uma vez que as plantas podem absorver diretamente o $\mathrm{N}$ presente no solo (OLIVEIRA et al., 2004). Por outro lado, o processo pode ocorrer com eficiência em condições de baixa disponibilidade de $\mathrm{N}$ no solo (FRANCO \& NEVES, 1992), embora seja recomendado o uso de pequenas doses de $\mathrm{N}$ aplicadas na semeadura (HUNGRIA et al., 1994) para melhorar o crescimento das plantas e promover efeito sinérgico sobre a nodulação (TSAl et al., 1993).

Segundo Hungria (2011) ao contrário das bactérias simbióticas, bactérias associativas como Azospirillum excretam somente uma parte do nitrogênio fixado diretamente para a planta associada, posteriormente, a mineralização das bactérias pode contribuir com aportes adicionais de nitrogênio para as plantas. Entretanto a autora relata que o processo de fixação biológica por essas bactérias consegue suprir apenas parcialmente as necessidades das plantas.

O objetivo deste trabalho foi estudar a influencia da inoculação de sementes de trigo com bactéria do gênero Azospirillun brasilense, em interação à aplicação de nitrogênio, sobre a produtividade e qualidade do trigo.

\section{MATERIAL E MÉTODOS}

O experimento foi conduzido durante os meses de abril a setembro de 2010 , na área agrícola do Sitio Nossa Senhora Aparecida, situada no município de São João do Ivaí - PR (latitude: $24^{\circ} 01^{\prime} 23^{\prime \prime} \mathrm{S}$, longitude: $51^{\circ} 47^{\prime} 33^{\prime \prime} \mathrm{W}$ e altitude de $508 \mathrm{~m}$ ). O clima da região classificação Cfa segundo a classificação de Köppen (OMETTO, 1981), sendo clima mesotérmico, sem estação seca definida. Os dados de índice pluviométrico coletados no período e no local de condução do trabalho encontram-se na Figura 1.

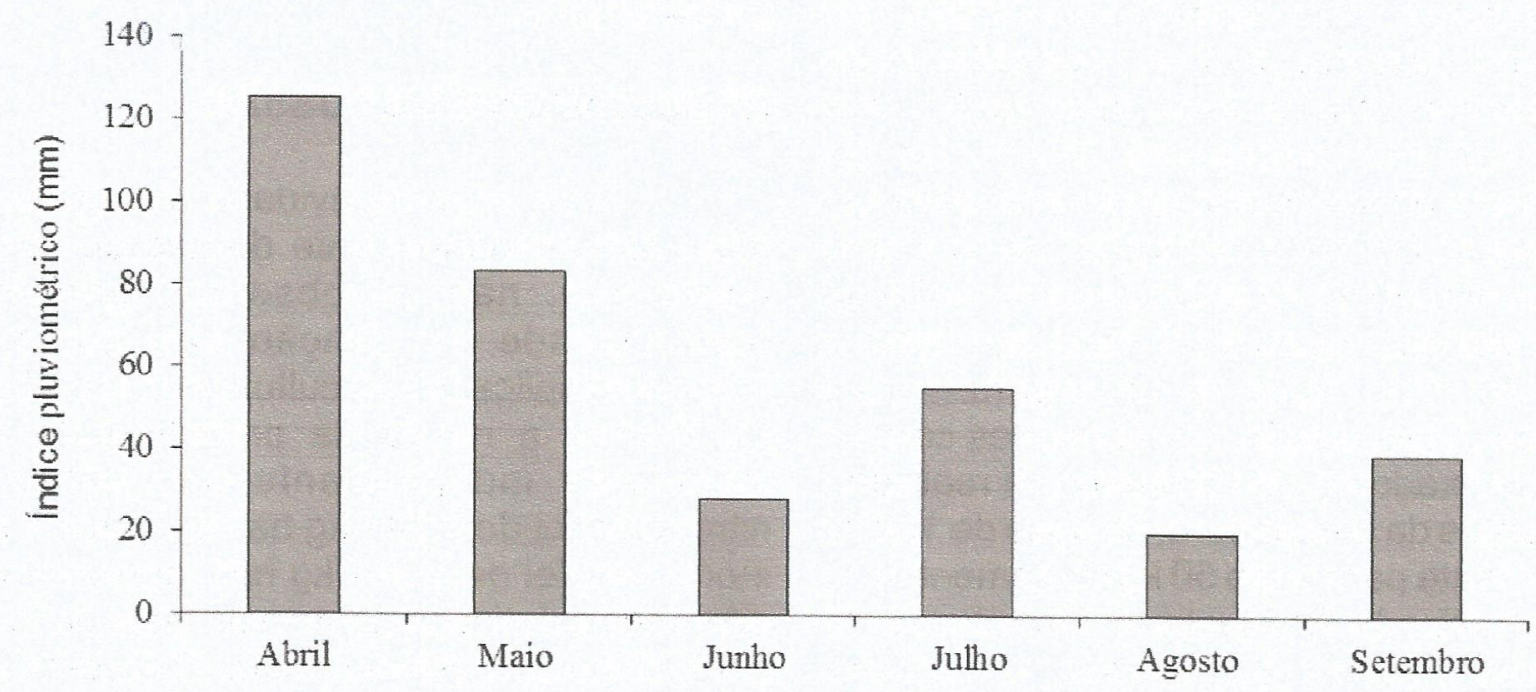

Figura 1. Índice pluviométrico do local do experimento durante o periodo de condução (abril a setembro de 2010). 
O solo da área experimental foi classificado como Latossolo Vermelho Distroférrico de textura argilosa (EMBRAPA, 1999), com relevo suave ondulado e boa drenagem, possuindo as seguintes características químicas e granulométricas: $\mathrm{pH}\left(\mathrm{C}_{\mathrm{a}} \mathrm{Cl}_{2}\right)$ de 5,$1 ; 19 \mathrm{~g} \mathrm{dm}^{-3}$ de $\mathrm{MO} ; 6,58 \mathrm{mg} \mathrm{dm}$ ${ }^{3}$ de $\mathrm{P}_{\text {Menlich; }} ; 35,5 \mathrm{mmol}_{\mathrm{c}} \mathrm{dm}^{-3}$ de $\mathrm{H}+\mathrm{Al} ; 1,4 \mathrm{mmol}_{\mathrm{c}}$ $\mathrm{dm}^{-3}$ de K; 45,9 $\mathrm{mmol}_{\mathrm{c}} \mathrm{dm}^{-3}$ de Ca; $9,4 \mathrm{mmol}_{\mathrm{c}}$ $\mathrm{dm}^{-3}$ de $\mathrm{Mg} ; 56,7 \mathrm{mmol}_{\mathrm{c}} \mathrm{dm}^{-3} \mathrm{de} \mathrm{SB} ; 92,1 \mathrm{mmol}_{\mathrm{c}}$ $\mathrm{dm}^{-3}$ de CTC; saturação por bases $61,5 \%$; teor de areia $40 \mathrm{~g} \mathrm{~kg}^{-1}$; teor de argila $804 \mathrm{~g} \mathrm{~kg}^{-1}$; teor de silte $156 \mathrm{~g} \mathrm{~kg}^{-1}$.

A área experimental vinha sendo cultivada por mais de dez anos no sistema plantio direto (SPD) consolidado, com rotação das lavouras de milho e/ou soja no verão, e/ou milho safrinha e trigo no inverno.

O material genético utilizado foi o cultivar de trigo CD-104, semeado no dia 30 de Abril de 2010, utilizando-se uma semeadora modelo TD 300 Semeato. Simultaneamente à semeadura foi realizada a adubação no sulco de semeadura com $220 \mathrm{~kg} \mathrm{ha}^{-1}$ de adubo na formulação 08-20-20. A densidade de semeadura foi de 450 sementes $\mathrm{m}^{-2}$, considerando 75 sementes viáveis por metro e espaçamento entre linhas de $0,17 \mathrm{~m}$.

O delineamento experimental utilizado foi em blocos inteiramente casualizados, com quatro repetições, no esquema fatorial $2 \times 4$, considerando tratamentos com e sem inoculação das sementes por bactérias fixadoras de nitrogênio e doses de nitrogênio aplicadas em cobertura $\left(0,65,100\right.$ e $145 \mathrm{~kg} \mathrm{ha}^{-1}$ de N). Como fonte de nitrogênio foi utilizada uréia $(45 \%$ de $\mathrm{N}$ ). As referidas doses de $\mathrm{N}$ foram aplicadas a lanço 30 dias após a emergência das plantulas. A inoculação das sementes com as bactérias fixadoras de nitrogênio foi realizada pouco antes da semeadura, na dose de $100 \mathrm{ml}$ de inoculante para cada $50 \mathrm{~kg}$ de sementes. $O$ produto utilizado foi Masterfix Gramineas da empresa Stoller do Brasil, o mesmo corresponde a uma concentração de 200 milhões de células de bactérias do gênero Azospirillum por ml do produto.

As unidades experimentais foram constituidas por parcelas com área de $15 \mathrm{~m}^{2}$, considerando $5 \mathrm{~m}$ de comprimento e $3 \mathrm{~m}$ de largura, com área útil de $10 \mathrm{~m}^{2}$, entreos blocos experimentais foram deixados corredores de $0,80 \mathrm{~m}$ de largura.

Imediatamente antes da colheita foi realizada a contagem de espiguetas por metro quadrado utilizando gabarito de $0,5 \times 0,5 \mathrm{~m}$. Após a maturação fisiológica dos grãos, fez-se a colheita manual em uma área útil de $2 \mathrm{~m}^{2}$ da parcela. Os grãos foram submetidos à trilha e limpeza a campo por uma trilhadora estacionaria. Após este processo, foi determinado o peso hectolitro (PH) dos grãos, por meio de balança eletrônica de precisão. Como também foi determinada a massa de 1000 grãos e a produtividade de grãos por hectare. Posteriormente, uma amostra dos grãos foi pesada e tiveram o teor de água determinado em laboratório, o qual foi utilizado para correção dos dados de $\mathrm{PH}$, massa de 1000 grãos e produtividade para $13 \%$ base úmida.

Os resultados foram submetidos à análise de regressão para ajustes de equações lineares ou quadráticas significativas até $5 \%$ de probabilidade pelo teste F. Quando houve diferença significativa entre tratamentos, a $5 \%$ de probabilidade pelo teste F, fizeram-se comparações das médias por meio do teste Tukey, também até $5 \%$ de probabilidade.

\section{RESULTADOS E DISCUSSÃO}

Para a produtividade de grãos de trigo, independentemente do uso ou não de inoculante, não se observou ganho de produtividade em função das doses de nitrogênio aplicadas na cultura do trigo (Figura 2). Porém, a média da produtividade com inoculante independente das doses de nitrogênio foi de $3.541 \mathrm{~kg} \mathrm{ha}^{-1}$ de grãos e sem inoculante foi de $3.241 \mathrm{~kg} \mathrm{ha}^{-1}$, apresentando diferença estatisticamente pelo teste de Tukey a $5 \%$ (Figura 6). Sendo assim, obteve-se uma diferença de 5,0 sacas ha-1 de grãos a mais na presença do inoculante (Figura 6). Sala et al. (2007) também constataram aumento na produtividade de grãos de trigo quando realizou-se a inoculação de Azospirillum, 
sendo que as melhores respostas foram obtidas nos tratamentos em que não foi utilizado nitrogênio adicional. Estes resultados podem estar atribuídos ao maior aporte de nitrogênio à planta promovido pelas bactérias do gênero Azospirillum (HUNGRIA, 2011; DIDONET etal., 2000).

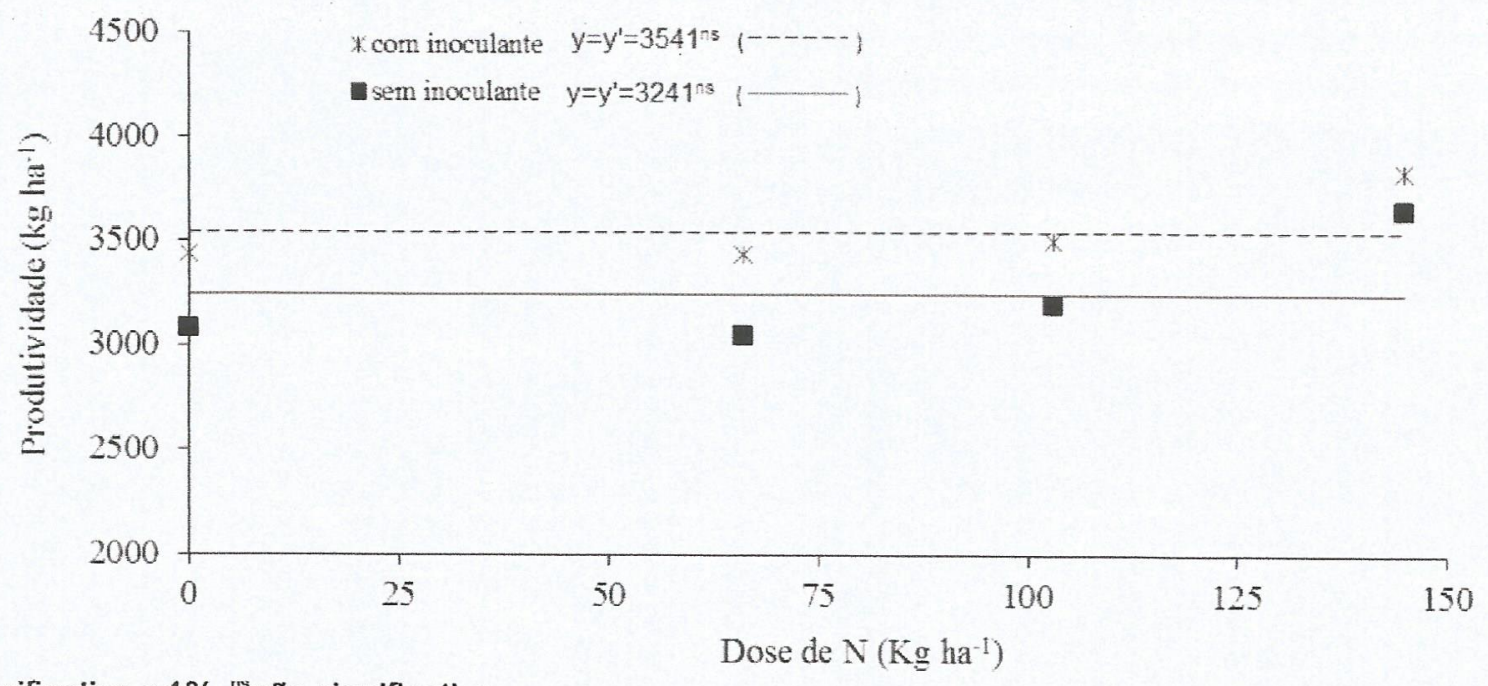

" significativo a 1\%, "'não significativo.

Figura 2. Produtividade de grãos de trigo em função da adubação nitrogenada, aplicada em cobertura nas doses de $0,65,100$, e $145 \mathrm{~kg} \mathrm{ha}^{-1}$ de $\mathrm{N}$, na interação de tratamentos com e sem inoculação das sementes, com bactérias fixadoras de nitrogênio.

O peso hectolitro $(\mathrm{PH})$ dos grãos de trigo (Figura 3 ) foi significativamente $(p<0,05)$ maior $(78,11 \mathrm{~kg})$ no tratamento com inoculação das sementes e sem $\mathrm{N}$ aplicado via cobertura, em relação aos tratamentos sem inoculação das sementes, entretanto, nota-se que a adubação nitrogenada reduziu este parâmetro quando foram aplicadas doses de 26 a $125 \mathrm{~kg} \mathrm{ha}^{-1}$ de $\mathrm{N}$, e quando utilizou-se doses acima de $125 \mathrm{~kg} \mathrm{ha}^{-1}$ de $\mathrm{N}$ o PH voltou a ser mais elevado do que os tratamentos sem inoculação. Estes resultados podem ter ocorrido em função da diminuição da população das bactérias Azospirillum no solo, na presença da adubação nitrogenada (Silva et al., 2004), assim o fornecimento de nitrogênio para a cultura passou a ser dependente do nitrogênio mineral (OLIVEIRA et al., 2004), onde as doses de 26 a $125 \mathrm{~kg} \mathrm{ha}^{-1}$ de $\mathrm{N}$ não supriram a necessidade das plantas por esse nutriente. Após o aumento do fornecimento de $\mathrm{N}$ mineral via cobertura (125 $\mathrm{kg} \mathrm{ha}^{-1}$ ), o nutriente passa suprir a cultura e aumenta o PH. A resposta do PH dos grãos de trigo quando não foi utilizada inoculação, corrobora com as respostas obtidas acima, apesar de não ser significativo, percebeu-se que o maior PH dos grãos de trigo foi obtida na maior dose de $\mathrm{N}$ avaliada, mostrando portanto que altas doses de $\mathrm{N}$ favorecem o aumento do $\mathrm{PH}$ dos grãos de trigo, independente do uso ou não da inoculação. Porém, Mendes et al. (2011) observaram que a inoculação de sementes de trigo com Azospirillum, aumentou o peso hectolitro e a produtividade de grãos de trigo.

Para os resultados da massa de 1000 grãos, verificou-se que houve resposta linear positiva com a aplicação de doses crescente de nitrogênio, na ausência de inoculante via semente (Figura 4). Entretanto esta resposta não foi observada quando as sementes foram inoculadas. Na comparação entre a aplicação de inoculante e sem inoculante independente da adubação nitrogenada em cobertura (Figura 7), observou-se que, com inoculação das sementes a massa de 1000 grãos foi maior $(41,75 \mathrm{~g})$ em relação a massa de 1000 grãos dos tratamentos em que as sementes não foram inoculadas $(37,92 \mathrm{~g})$, justificando assim a maior produtividade por hectare promovido pela inoculação das sementes 
(Figura 2). Estas respostas ocorrem em razão da inoculação das sementes com Azospirillum promover maior aporte de $\mathrm{N}$ para as plantas, consequentemente promovendo maior eficiência deste nutriente para os grãos, produzindo grãos mais pesados (DIDONET et al., 2000). Segundo Prado (2008) o nitrogênio promove o aumento da área foliar das plantas, favorecendo o aumento da taxa fotossintética da mesma, em com isso há maior fluxo de carboidrato para os grãos e consequentemente aumenta o desenvolvimento dos mesmos.

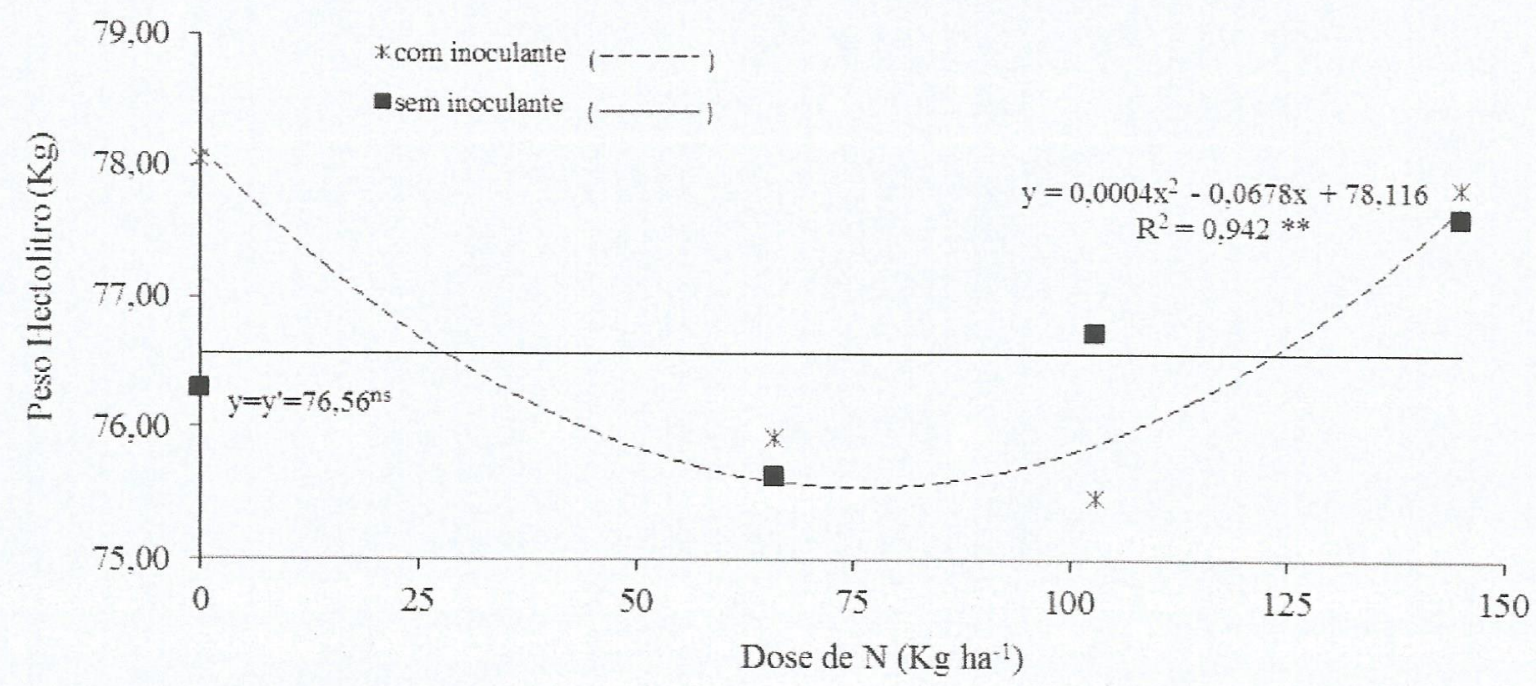

** significativo a $1 \%$, "não signiïıcatıvo.

Figura 3. Peso Hectolitro dos grãos de trigo em função da adubação nitrogenada, aplicada em cobertura nas doses de $0,65,100$, e $145 \mathrm{~kg} \mathrm{ha}^{-1}$ de $\mathrm{N}$, na interação de tratamentos com e sem inoculação das sementes, com bactérias fixadoras de nitrogênio.

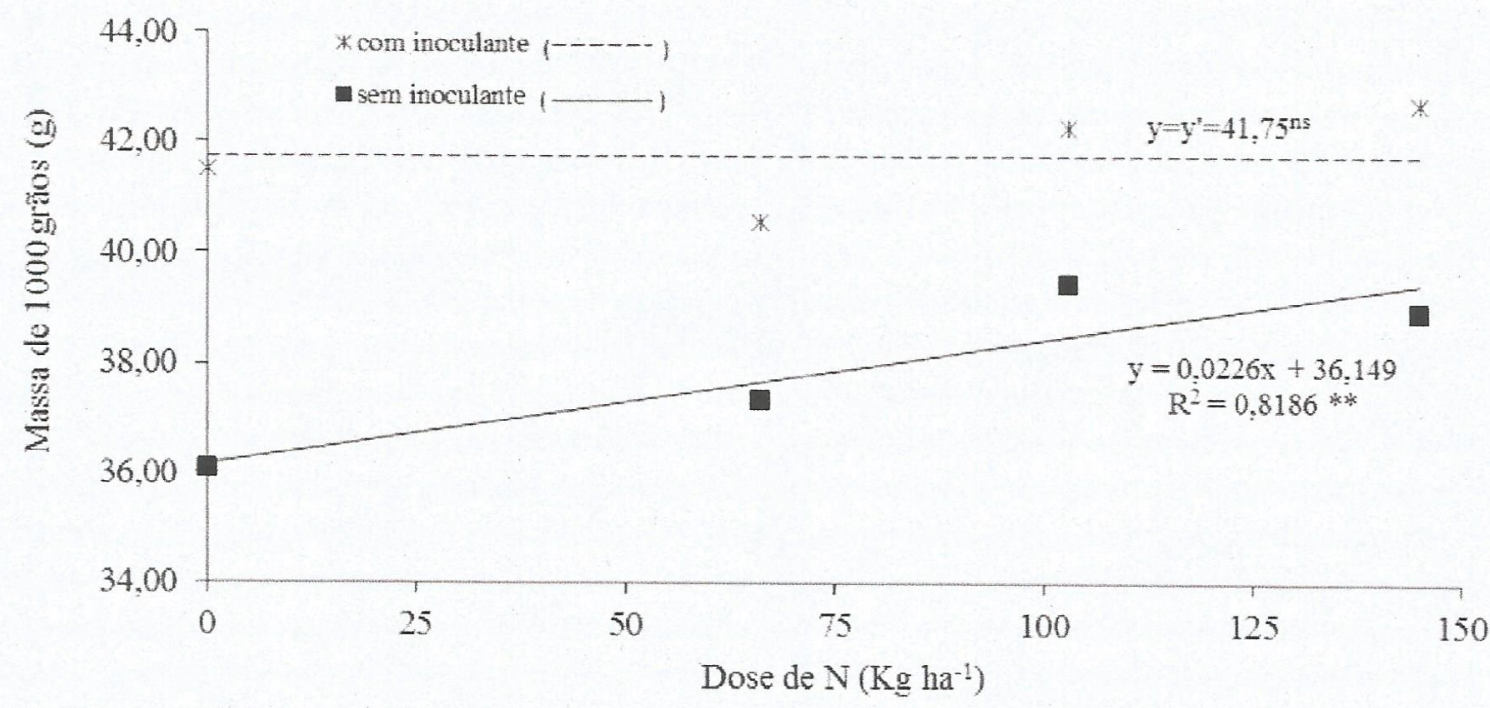

** significativo a $1 \%,{ }^{\text {ns }}$ não significativo.

Figura 4. Massa de 1000 grãos de trigo em função da adubação nitrogenada, aplicada em cobertura nas doses de $0,65,100$, e $145 \mathrm{~kg} \mathrm{ha}^{-1}$ de $\mathrm{N}$, na interação de tratamentos com e sem inoculação das sementes, com bactérias fixadoras de nitrogênio. 
Com relação ao número de espigas observado efeito tanto das doses de $\mathrm{N}$ como por metro quadrado (Figura 5) não foi também do uso da inoculação.

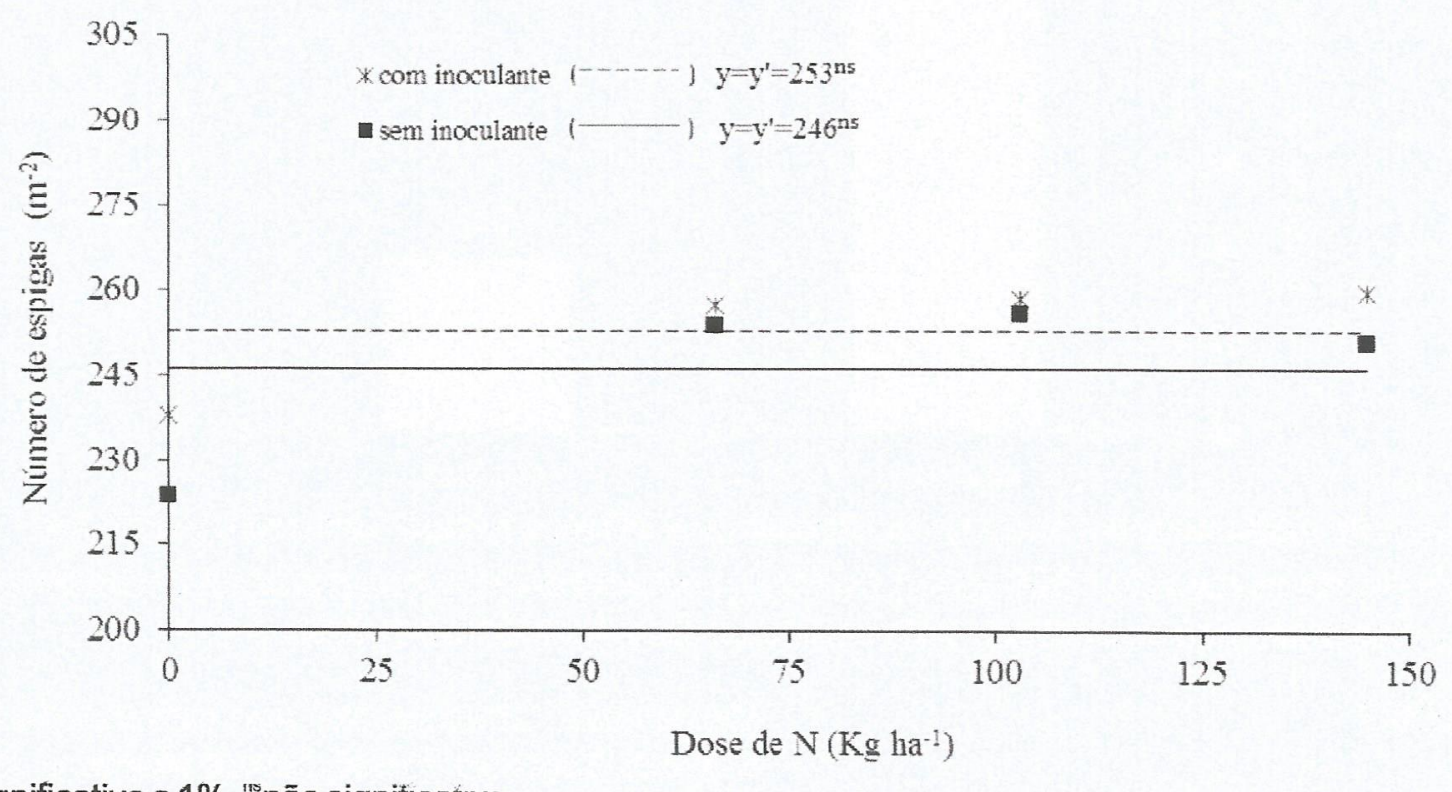

** significativo a 1\%, "'são significatıvo.

Figura 5. Número de espigas de trigo por metro quadrado em função da adubação nitrogenada, aplicada em cobertura nas doses de $0,65,100$, e $145 \mathrm{~kg} \mathrm{ha}^{-1}$ de N, na interação de tratamentos com e sem inoculação das sementes, com bactérias fixadoras de nitrogênio.

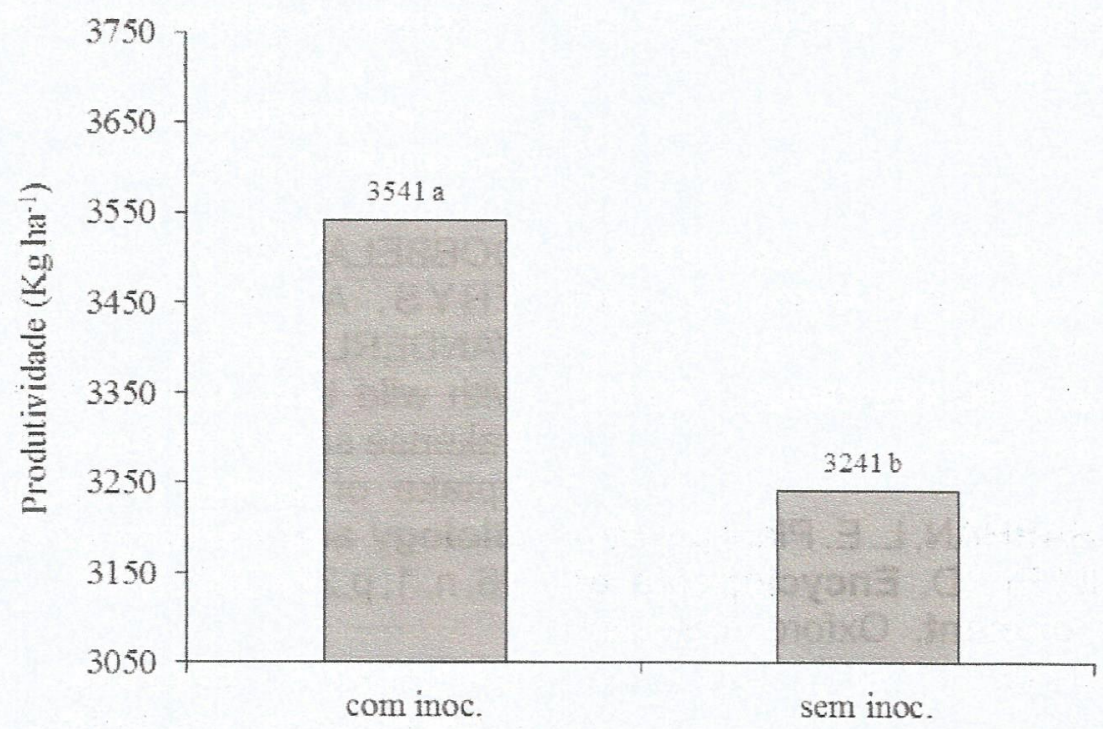

As letras seguidas da média indicam a diferença significativa $(p<0,05)$ entre os tratamentos pelo teste Tukey.

Figura 6. Média da produtividade de grãos de trigo, considerando a comparação do tratamento, com e sem inoculação das sementes, com bactérias fixadoras de nitrogênio. 


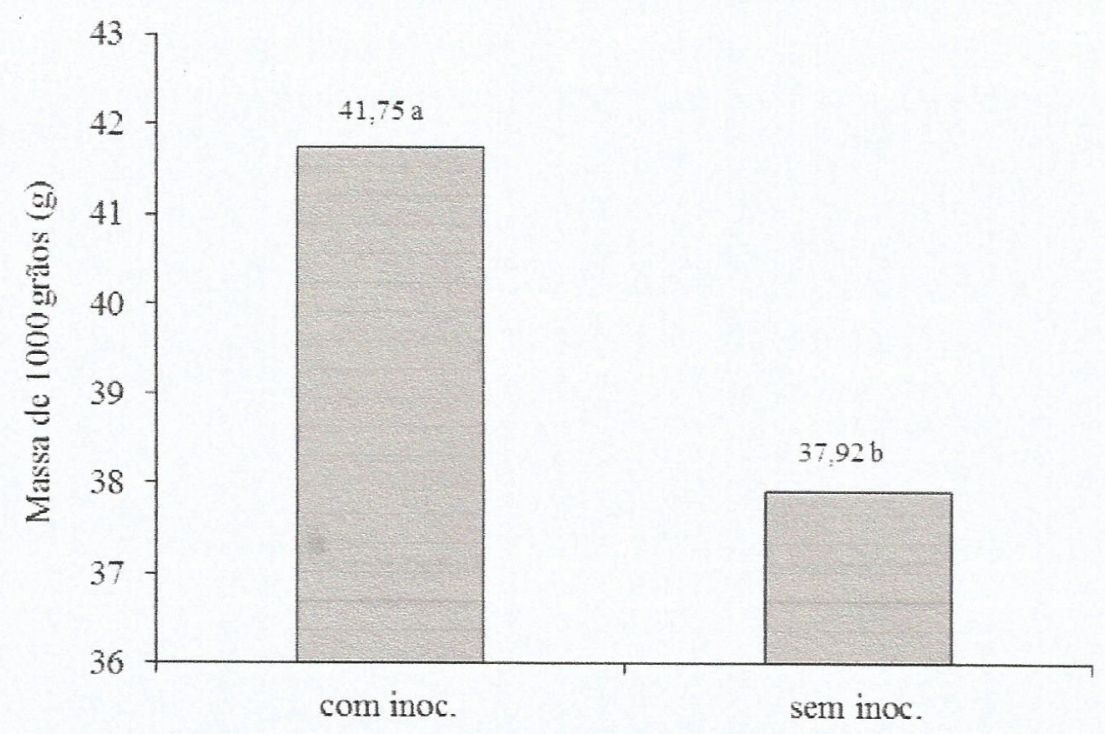

As letras seguidas da média indicam a diferença significativa $(p<0,05)$ entre os tratamentos pelo teste Tukey.

Figura 7. Média da massa de 1000 grãos de trigo, considerando a comparação do tratamento, com e sem inoculação das sementes, com bactérias fixadoras de nitrogênio.

\section{CONCLUSÕES}

A inoculação de sementes de trigo com Azospirillum brasilense promoveu o aumento da massa de 1000 grãos e produtividade, independente da aplicação de nitrogênio em cobertura. Na ausência de inoculação das sementes a adubação nitrogenada promoveu e incremento da massa de 1000 grãos.

\section{REFERÊNCIAS}

BASHAN, Y:; HOLGUIN, G. Azospirillum plant relationships: environmental and physiological advances (1990-1996). Canadian Journal of Microbiology, Ottawa, v. 43, n.1, p.103-121, 1997.

BASHAN, Y.; DE-BASHAN, L. E. Plant growthpromoting. In: HILLEL, D. Encyclopedia of soil in the environment. Oxford, Elsevier, 2005. cap. 8, p.103-115.

BODDEY, R. M.; BALDANI, V. L. D.; BALDANI, J. I.; DÖBEREINER, J. Effect of inoculation of Azospirillum spp on the nitrogen assimilation of field grown wheat. Plant and Soil, New York, v. 95, n. 1, p.109-121, 1986.

CAMPOS, B. H. C.; THEISEN, S.; GNATTA, V.
Inoculante "Graminante" nas culturas de trigo e aveia. Ciência Rural, Santa Maria, v. 23, n. 3, p.401-407, 1999.

DIDONET, A. D.; LIMA, O. D. S.; CANDATEN, A. A.; RODRIGUES, O. Realocação de nitrogênio e de biomassa para os grẳos, em trigo submetido à inoculação de Azospirillum. Pesquisa Agropecuária Brasileira, Brasilia, v. 35, n. 2, p.401-411, 2000. Disponível em: < http://www.scielo.br/pdf/pab/v35n2/6886.pdf> . Acesso em: 05 fev. 2013.

DOBBELAERE, S.; CROONENBORGHS, A.; THYS, A.; PTACEK, D.; OKON, Y.; VANDERLEYDEN, J. Effect of inoculation with wild type Azospirillum brasilense an A. irakense strains on development and nitrogen uptake of spring wheat and grain maize. Biology and Fertility of Soils, New York, v. 36, n. 1, p.284-297, 2002.

EMBRAPA. Sistema Brasileiro de classificação de solos. Rio de Janeiro: Embrapa Solos, 1999.414 p.

FRANCO, A. A.; NEVES, M. C. P. Fatores limitantes à fixação biológica de nitrogênio. In: CARDOSO, E.J.B.N. et al. (Eds). Microbiologia do solo. Campinas: SBCS, 1992. cap. 11, p.257-282. 
HUNGRIA, M. et al. Fixação biológica do nitrogênio em soja. In: ARAUJO, R. S.; HUNGRIA, M. (Eds). Microrganismos de importâncía agrícola. Brasília: Embrapa,1994. cap.2, p.9-90.

HUNGRIA, M. Inoculação com Azospirillum brasilense: inovação em rendimento a baixo custo. Londrina: Embrapa soja, 2011. 36 p. (Documentos / Embrapa Soja, n. 325).

INIGUEZ, A. L.; DONG, Y.; TRIPLETT, E. W. Nitrogen fixation in wheat provided by Klebsiella pneumoniae 342. Molecular Plant Microbiology, Saint Paul, v. 17, n. 10, p.10781085, 2004.

LOPES, A. S.; WIETHÖLTER, S.; GUILHERME, L. R. G.; SILVA, C. A. Sistema plantio direto: bases para o manejo da fertilidade do solo. São Paulo: Associação Nacional para Difusão de Adubos, 2004. 115 p.

MENDES, M. C.; ROSẢRIO, J. G.; FARIAS, M.

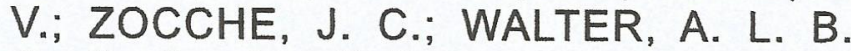
Avaliação da eficiência agronômica de Azospirillum brasilense na cultura do trigo e os efeitos na qualidade de farinha. Revista Brasileira de Tecnologia Aplicada nas Ciências Agrárias, Guarapuava, v. 4, $n$. 3,p.95-110, 2011.

OMETTO, J. C. Bioclimatologia vegetal. São Paulo: Agronômica Ceres Ltda., 1981. $440 \mathrm{p}$.

OKON, Y.; LABANDERA-GONZALES, C. A. Agronomic applications of Azospirillum: an evaluation of 20 years worldwide field inoculation. Soil Biology and Biochemistry, Oxford, v. 26, n. 1, p.1591-1601, 1994.

PEDROSA, F. O. Fixação Biológica de Nitrogênio: Fértil Ideia. Ciência Hoje, São Paulo, v. 6, n. 1, p.12-13, 1987.

OLIVEIRA, W. S. et al. Alfalfa yield and quality as function of nitrogen fertilization and symbiosis with Sinorhizobium meliloti. Scientia Agricola, Piracicaba, v. 61, n. 4, p.433-438, 2004.

PRADO, R. M. Nutrição de Plantas. 1. ed. São Paulo: Editora UNESP, 2008, 408 p.

RODRIGUES, O.; DIDONET, A. D.; GOUVEIA, J. A.; SOARES, R. C. Nitrogen translocation in wheat inoculated with Azospirillum and fertilized with nitrogen. Pesquisa Agropecuária Brasileira, Brasília, v. $35, n .7$, p.1473-1481, 2000.

SALA, V. M. R.; CARDOSO, E. J. B. N.; FREITAS, J. G.; SILVEIRA, A. P. D. Resposta de genótipos de trigo à inoculação de bactérias diazotróficas em condições de campo. Pesquisa Agropecuária Brasileira, Brasilia, v. 42, n. 6, p.833-842, 2007.

SILVA, D. M.; FRIES, M. R.; ANTONIOLLI, Z. I.; AITA, C.; VOSS, M.; JACQUES, R.; SEMINOTTI, J.; CARVALHO, C. A. Bactérias diazotróficas em solo cultivado com arroz irrigado (Oryza satival.) Revista brasileira de Agrociência, Pelotas, v. 10, n. 4, p.467-474, 2004.

TAIZ, L.; ZEIGER, E. Fisiologia vegetal. 4. ed. Porto Alegre:Artmed Editora, 2009. 848 p.

TSAI, S. M. et al. Minimizing the effect of mineral nitrogen on biological nitrogen fixation in common bean by increasing nutrient levels. Plant and Soil, New York, v. 152, n. 1, p.131138, 1993

ZAIED, K. A.; EL-HADY, A. H.; AFIFY, A. H.; NASSEF, M. A. Yield and nitrogen assimilation of winter wheat inoculated with new recombinant inoculants of rhizobacteria. Pakistan. Journal of Biological Sciences, Londres, v. 4, n. 1, p.344-358, 2003. 
